\title{
The Distribution of Platinum and Palladium Metals in Iron Meteorites and in the Metal Phase of Ordinary Chondrites ${ }^{1}$
}

\author{
Waiter Nichiporuk and Harrison Brown \\ Division of Geological Sciences \\ California Institute of Technology, Pasadena
}

\begin{abstract}
The concentrations of $\mathrm{Ru}, \mathrm{Rh}, \mathrm{Pd}, \mathrm{Ir}$, and $\mathrm{Pt}$ have been determined spectrographically in twenty-four iron meteorites and in the metal phase of five ordinary chondrites. It was found that most iron meteorites fall into three distinct groups with regard to the $\mathrm{Ru}$ and $\mathrm{Rh}$ concentrations and into three groups with regard to the Ir and $\mathrm{Pt}$ concentrations, each Ir-Pt group corresponding to one of the $\mathrm{Ru}-\mathrm{Rh}$ groups. Correlations are observed between these Ir-Pt and Ru-Rh groups on the one hand, and the Ga-Ge groups found by previous workers on the other, but the relationships are by no means clear-cut. Compared with $\mathrm{Ru}$, Ir, and $\mathrm{Pt}, \mathrm{Pd}$ was found to vary over a relatively small range. The metal phases of all chondrites studied are chemically identical with the iron meteorites of the largest Ru-Rh and the largest Ir-Pt group, namely the Ru-Rh group which contains about $6 \mathrm{ppm} \mathrm{Ru}$ and $1.5 \mathrm{ppm} \mathrm{Rh}$, and the Ir-Pt group which contains about $2 \mathrm{ppm}$ Ir and $7 \mathrm{ppm}$ Pt. The following atomic abundances $\left(\mathrm{Si}=10^{\circ}\right)$ of $\mathrm{Ru}, \mathrm{Rh}, \mathrm{Pd}, \mathrm{Ir}$, and $\mathrm{Pt}$ have been derived from our data:
\end{abstract}

$\begin{array}{lccccc} & \mathrm{Ru} & \mathrm{Rh} & \mathrm{Pd} & \mathrm{Ir} & \mathrm{Pt} \\ \begin{array}{llll}\text { Based on metal phase of high-iron-group chondrites } \\ \begin{array}{l}\text { Based on iron meteorites, assuming they constitute 10\% } \\ \text { of mean meteoritic matter }\end{array}\end{array} & 1.66 & 0.27 & 1.05 & 0.40 & 1.22 \\ & 1.44 & 0.23 & 0.52 & 0.31 & 0.89\end{array}$

These values generally agree within a factor of less than 2 with the abundances calculated by recent workers.

\section{INTRODUCTION}

Pt and Pd metals are concentrated almost entirely in the metal phase ${ }^{2}$ of meteoritic matter. In view of this, it is desirable that accurate determinations of their distribution in iron meteorites and in the metal phase of chondrites be obtained. Abundances of these elements have been determined spectroscopically in iron meteorites by Noddack and Noddack [1930] and also by Goldschmidt and Peters [1932], but the estimates are only approximate [Suess and Urey, 1956]. Goldschmidt [1938] averaged these analyses and Suess and Urey [1956] reported interpolated values. Table 1 lists the average

\footnotetext{
${ }_{1}$ Contribution 1275, Division of Geological Sciences, Seeley W. Mudd Laboratory, California Institute of Technology, Pasadena.

${ }^{2}$ We thank Dr. Goles for pointing out to us that the metal phase as used in this paper is not a phase in the strict sense but rather is a mixture of true phases, kamacite and taenite, which were not separated in this investigation.
}

concentrations of $\mathrm{Pt}$ and $\mathrm{Pd}$ metals in iron meteorites selected by previous investigators.

Brown and Goldberg [1949] and Goldberg et al. [1951] have determined Pd in forty-five iron meteorites by neutron activation, and Hara and Sandell [1960] have determined $\mathrm{Ru}$ in seventeen iron meteorites and in the metal phase of two pallasites by absorption spectrophotometry. Herr et al. [1958] have also determined $\mathrm{Ru}$ in the Carbo iron meteorite by neutron activation. The ranges of concentration obtained by all these workers are shown in Table 2 and compared with the ranges of concentration observed in this study.

The averages and the precision of the data of Goldberg et al. for $\mathbf{P d}$ are respectively $3.7 \mathrm{ppm}$ and approximately $10 \%$, and those of the data of Hara and Sandell for Ru are respectively 6.6 ppm and about 5\%.

As we shall see, the ranges of concentration observed in this study of $\mathrm{Ir}, \mathrm{Pt}$ (see also Nichiporuk and Brown [1962]), and Rh in iron meteorites are just as large as if not larger than 
TABLE 1. Abundances of Pt and Pd Metals in Iron Meteorites Selected by Previous Investigators

\begin{tabular}{lccc}
\hline & $\begin{array}{c}\text { Goldschmidt } \\
{[1938]}\end{array}$ & Browm [1949] & $\begin{array}{c}\text { Suess and } \\
\text { Urey [1956] }\end{array}$ \\
Metals & & 10.6 & 10 \\
Ru, ppm & 10 & 4.1 & 144 \\
Rh, ppm & 5 & $3.7^{*}$ & 5.7 \\
Pd, ppm & 9 & 7.6 & 12.2 \\
Os, ppm & 8 & 3.0 & 101 \\
Ir, ppm & 4 & 19 & 202 \\
Pt, ppm & 20 & & \\
\hline
\end{tabular}

*The average of determinations by Browm and Goldberg [1949].

the ranges of concentrations of $\mathrm{Pd}$ and $\mathrm{Ru}$. By comparison, the ranges of concentration of $\mathrm{Pt}$ and $\mathrm{Pd}$ metals in the metallic-iron phase of ordinary, high-iron-group chondrites were found to be very small.

\section{Analytical Methods}

$\mathrm{Pt}$ and $\mathrm{Pd}$ metals were isolated from iron meteorites and the metal phase of chondrites by precipitation as sulfides and were determined spectrographically.

Samples ranging in weight from 8 to $20 \mathrm{~g}$ were cut from larger portions of iron meteorites, care being taken to avoid discernible inclusions of troilite, schreibersite, and cohenite. Samples of Huizopa, Indian Valley, and Tazewell were in the form of fine sawings and were residues from other work. All samples were washed in $6 \mathrm{~N} \mathrm{HCl}$, quadruply distilled water, and ethyl alcohol to remove surface impurities.

Specimens of chondrites weighing 70 to $90 \mathrm{~g}$ were crushed in a Plattner mortar to about 100 mesh and separated into 'magnetic' and 'nonmagnetic' fractions with a hand magnet. The 'magnetic' fractions used in this work were composed of metallic grains with inclusions of fine silicate and troilite particles which were embedded in the grains during the crushing process. The 'magnetic' fractions ranged in weight from 7 to $13 \mathrm{~g}$.

All chemistry was performed in pyrex glassware which before use had been thoroughly washed and kept for at least 2 hours in hot, concentrated, reagent grade $\mathrm{HNO}_{3}$. The samples were brought into solution in $400-\mathrm{ml}$ beakers in a mixture of hot, concentrated $\mathrm{HCl}$ and $\mathrm{HNO}_{\mathbf{s}}$. The $\mathrm{HCl}$ was obtained by bubbling tank
$\mathrm{HCl}$ gas into distilled water in a flask. $\mathrm{HNO}_{3}$ was distilled under vacuum in a quartz still. The residue was filtered, dried, and weighed; nitrate was destroyed by evaporation with $\mathrm{HCl}$. The solution was made $8.1 \mathrm{~N}$ in $\mathrm{HCl}$, then transfered into a 1-liter separatory funnel. This solution contained all $\mathrm{Pt}$ and $\mathrm{Pd}$ metals except Os.

The $\mathrm{Fe}$ (as $\mathrm{HFeCl}_{4}$ ) was extracted twice with 600-ml portions of redistilled isopropyl ether [Dodson et al., 1936; Nachtrieb and Fryxell, 1948], and the aqueous $\mathrm{HCl}$ layer containing the metals was drawn off into a $200-\mathrm{ml}$ Berzelius beaker. After the addition of $40 \mathrm{mg}$ of $\mathrm{Cu}$ as a carrier and $0.5 \mathrm{mg}$ of Mo as an internal standard, the aqueous layer was evaporated to about $20 \mathrm{ml}$ and then saturated with $\mathrm{Cl}_{2}$ gas to oxidize all Mo to the +6 state. The solutions were evaporated to dryness and the solids were dissolved in $20 \mathrm{ml}$ of $1.5 \mathrm{~N} \mathrm{HCl}$ which contained $\mathrm{AlCl}_{3} \cdot 6 \mathrm{H}_{2} \mathrm{O}$ as a coagulant for $\mathrm{Ir}$ sulfide. The $\mathrm{Ru}, \mathrm{Rh}, \mathrm{Pd}, \mathrm{Ir}$, and Pt sulfides were precipitated with $\mathrm{Cu}$ and $\mathrm{Mo}$ sulfides by bubbling $\mathrm{H}_{2} \mathrm{~S}$ gas into warm solutions in 200-ml beakers for 3 hours and allowing the precipitates and supernates to stand for 48 hours. The sulfides were collected in sintered glass crucibles, and the precipitation was repeated. The two precipitates were thoroughly mixed in dilute $\mathrm{HCl}$ and ethyl alcohol and dried at $100^{\circ} \mathrm{C}$; their weights ranged from 120 to $130 \mathrm{mg}$ for all samples analyzed.

All compounds and metals used in this work were 'specpure' grade, obtained from Johnson, Matthey and Co., Ltd. A series of standards was prepared containing from 15 to $4000 \mathrm{ppm}$ of each metal and $1.0 \mathrm{mg}$ of Mo as an internal standard. The metals were present in a matrix of 120 to $130 \mathrm{mg}$ of CuS. The standard solutions composed of $15 \mathrm{~g}$ of $\mathrm{Fe}, 1.4 \mathrm{~g}$ of $\mathrm{Ni}$, and $0.08 \mathrm{~g}$ of Co were converted into $\mathrm{Cu}-\mathrm{M}$ o sulfides in the same manner as the meteorite solutions, thus

TABLE 2. Ranges of Concentration of Pd and $\mathrm{Ru}$ in Iron Meteorites As Found by Previous Workers and in This Study

\begin{tabular}{lcc}
\hline \multicolumn{1}{c}{ Investigators } & $\mathrm{Ru}, \mathrm{ppm}$ & $\mathrm{Pd}, \mathrm{ppm}$ \\
\hline Goldbert et al. $[1951]$ & & $1.44-9.88$ \\
Herr et al. $[1958]$ & $52.4 \pm 1.5$ & \\
Hara and Sandell $[1960]$ & $0.8-14.8$ & \\
This work & $0.5-23.7$ & $1.45-6.47$ \\
\hline
\end{tabular}


ensuring close physical and chemical resemblence of both samples and standards. Inasmuch as iron meteorites contain about $10 \mathrm{ppm} \mathrm{Mo}$ [Kuroda and Sandell, 1954], an equivalent amount of the element $(0.17 \mathrm{mg})$ was added to each standard solution before its extraction with ether.

To establish whether significantly variable yields of the investigated metals might have been obtained, minute quantities of $\mathrm{Os}^{101}(\beta$-particle emitter $0.18 \mathrm{Mev}, 15$ days half-life) tracer were added to three $\mathrm{HCl}$ solutions of $\mathrm{Fe}$, each of which contained $\mathrm{Ni}$ and $\mathrm{Co}$, and the measured traces of all $\mathrm{Pt}$ and $\mathrm{Pd}$ metals. Within a counting accuracy of $5 \%$, the yields of $\mathrm{Os}^{101}$, corrected for absorption and scattering effects in a matrix of $\mathrm{Cu}$ and Mo sulfides, were found to be constant.

As ions of all $\mathrm{Pt}$ and $\mathrm{Pd}$ metals are expected to behave similarly, it appears reasonably certain that the yields of $\mathrm{Ru}, \mathrm{Rh}, \mathrm{Pd}, \mathrm{Ir}$, and $\mathrm{Pt}$, like the yields of Os, which were not determined in this study, did not vary appreciably under the conditions of the enrichment procedures described.

The standards and samples were exposed using the following equipment and methods:

Spectrograph. Jarrell-Ash 3.4-m grating instrument with 15-thousand-lines-per-inch grating; Wadsworth mount, dispersion $5.2 \mathrm{~A} / \mathrm{mm}$ in first order.

Electrodes. High-purity $1 / 4$-in. graphite rods as anode. Pointed $1 / 8$-in. rods as cathode.

Excitation. 10-amp de arc (13-amp short circuit) from a Jarrell-Ash Uni-source. Sample as anode. Analytical gap $4 \mathrm{~mm}$ magnified $5 \times$ and focused on the slit. Central $2 \mathrm{~mm}$ used with a slit width of $10 \mu$. Samples and standards ground with pure quartz in proportions of 1 to 0.5 , and $25-\mathrm{mg}$ portions burned to completion after an initial pre-arcing at 2.5 to $3.0 \mathrm{amp}$; total time of burning $4 \mathrm{~min}$. Total energy method with internal standardization.

Wavelengths. The analytical lines used were $\mathrm{Ru} 3436.737 \mathrm{~A}, \mathrm{Rh} 3396.85 \mathrm{~A}, \mathrm{Pd} 3421.24 \mathrm{~A}, \mathrm{Ir}$ 2543.971 A, Ir 2849.725 A, and Pt 2659.454 A. The internal standard line was Mo $2816.154 \mathrm{~A}$ (singly ionized molybdenum).

Plates. Eastman Kodak III-0 developed for $4 \mathrm{~min}$ at $20^{\circ} \mathrm{C}$ in DK-50 developer, $30 \mathrm{sec}$ in short stop, $10 \mathrm{~min}$ in acid fix, and $20 \mathrm{~min}$ wash.
Plate calibration. Thirteen selected iron lines. Each plate was calibrated, and standards, including a blank, were exposed on each plate.

Densitometer. Jarrel-Ash model 2100.

Sensitivity. Ru 30 ppm; Rh 10 ppm; Pd 10 ppm; Ir (Ir 2849.725 A) 30 ppm; Pt 15 ppm; in a matrix of copper and molybdenum sulfides corrected for quartz dilution and assuming $100 \%$ precipitation yields of the metals.

\section{Precision and Accuracy}

The concentration of Ir in the Bear Creek, Sandia Mountains, and Sikhote-Alin meteorites was somewhat below the sensitivity limits of the element in the enriched samples under the conditions described. All samples were exposed between two and four times, and the arithmetic mean is reported.

An indication of the precision of the method may be obtained from the data on six iron meteorites shown in Table 3. The duplicate samples were of approximately equal size and were taken from either adjoining or separated locations of each of the six meteorites listed.

The differences between two samples could arise in part from possible variations in chemical yields, from spectrographic errors (e.g., due to self-absorption in the analytical lines at higher concentrations of the metals), from the inhomogeneity of the samples, and from con-

TABLE 3. Concentrations of Five $\mathrm{Pd}$ and $\mathrm{Pt}$ Metals in Duplicate Samples of Six Iron Meteorites

\begin{tabular}{|c|c|c|c|c|c|}
\hline $\begin{array}{l}\text { Name of } \\
\text { Meteorite }\end{array}$ & $\begin{array}{l}\mathrm{Ru}, \\
\mathrm{ppm}\end{array}$ & $\begin{array}{l}\mathrm{Rh}, \\
\mathrm{ppm}\end{array}$ & $\begin{array}{l}\text { Pd, } \\
\text { ppm }\end{array}$ & $\begin{array}{l}\text { Ir, } \\
\text { ppm }\end{array}$ & $\begin{array}{l}\text { Pt, } \\
\text { ppm }\end{array}$ \\
\hline Arispe I & 15.1 & 1.7 & & 73 & \\
\hline Arispe II & 123 & 1.7 & 3.1 & 7.9 & 17.2 \\
\hline Canyon Diablo I & 5.9 & 15 & & 16 & 66 \\
\hline Canyon Diablo II & {$[6.9$} & 15 & 36 & 1.9 & 81 \\
\hline Henbury I & 65 & 14 & 4.4 & 27 & 64 \\
\hline Henbury II & 56 & 1.1 & 34 & 19 & 49 \\
\hline Mount Tabby I & 17.6 & 22 & 28 & 105 & 252 \\
\hline Mount Tabby II & 15.6 & 2.3 & 3.3 & 7.6 & 21.9 \\
\hline Odessa I & 60 & 1.3 & & 19 & 89 \\
\hline Odessa II & 60 & 1.4 & 3.7 & 1.8 & 81 \\
\hline Toluca I & 4.9 & 1.0 & & 19 & 7.5 \\
\hline 'Toluca II & 5.7 & 1.2 & 4.0 & 2.2 & 56 \\
\hline
\end{tabular}


TABLE 4. Ru and Pd Contents of Iron Meteorites Determined by Different Methods of Analysis*

\begin{tabular}{|c|c|c|c|c|c|}
\hline \multirow[b]{2}{*}{$\begin{array}{l}\text { Name of } \\
\text { Meteorite }\end{array}$} & \multirow[b]{2}{*}{ Class } & \multicolumn{2}{|c|}{$\mathbf{R u}, \mathbf{p p m}$} & \multicolumn{2}{|c|}{$\mathrm{Pd}, \mathrm{ppm}$} \\
\hline & & $\begin{array}{c}\text { Photometric, } \\
\text { Hara and Sandell } \\
\text { [1960] }\end{array}$ & $\begin{array}{l}\text { Spectrographic, } \\
\text { This Work }\end{array}$ & $\begin{array}{c}\text { Neutron Activation, } \\
\text { Goldberg el al. } \\
\text { [1951] }\end{array}$ & $\begin{array}{l}\text { Spectrographic, } \\
\text { This Work }\end{array}$ \\
\hline Altonah & Of & 3.6 & 4.7 & 4.45 & 4.2 \\
\hline Arispe & $\mathrm{Og}$ & 10.0 & 13.7 & 2.69 & 3.1 \\
\hline Bear Creek & $\mathrm{Om}$ & & & 5.57 & 5.4 \\
\hline Bristol & Of & & & 4.36 & 3.9 \\
\hline Canyon Diablo & Og & 5.9 & 6.4 & 3.98 & 3.6 \\
\hline Cape of Good Hope & D & & & 7.07 & 4.1 \\
\hline Coahuila & $\mathrm{H}$ & & & 1.44 & 2.0 \\
\hline Costilla Peak & Om & 12.4 & 13.4 & 2.02 & 2.5 \\
\hline Coya Norte & $\mathrm{H}$ & 14.8 & 15.2 & & \\
\hline Edmonton & Of & 0.8 & 0.5 & 597 & 6.5 \\
\hline Goose Lake & Om & 4.6 & 6.4 & 3.34 & 3.9 \\
\hline Henbury & $\mathrm{Om}$ & 3.6 & 6.0 & 2.02 & 3.9 \\
\hline Indian Valley & $\mathbf{H}$ & & & 1.54 & 1.5 \\
\hline Odessa & Og & & & 4.15 & 3.7 \\
\hline Sandia Mountains & $\mathbf{H}$ & 7.5 & 7.2 & 2.24 & 2.1 \\
\hline Spearman & $\mathrm{Om}$ & 4.8 & 4.6 & 3.67 & 2.9 \\
\hline Tazewell & Off & & & 7.73 & 5.7 \\
\hline Toluca & Om & & & 4.72 & 4.0 \\
\hline
\end{tabular}

* Most of the specimens for which comparisons are made in this table are from the original collection used by Goldberg et al. [1951].

tamination of the samples with troilite or schreibersite.

The average deviation from the mean is estimated to be $8 \%$ for $\mathrm{Ru}, 10 \%$ for $\mathrm{Rh}, 9 \%$ for $\mathrm{Pd}, 17 \%$ for Ir, and $12 \%$ for Pt.

To obtain an indication regarding the accuracy of the spectrographic method a comparison was made of the $\mathrm{Pt}$ and $\mathrm{Pd}$ metal results in this work with the results obtained by Goldberg et al. [1951], by Hara and Sandell [1960], and by Yavnel' [1950]. Further, the Ir results on the metal phase of several chondrites were compared with those obtained by Rushbrook and Ehmann [1962].

From the comparisons presented in Table 4 it can be seen that spectrographic $\mathrm{Ru}$ determinations are generally about 20 to $30 \%$ higher than those determined by absorption spectrophotometry. Pd determined spectrographically actually shows two trends. At concentrations below about $3 \mathrm{ppm}$ spectrographic Pd determinations tend to be higher than Pd determined by neutron activation; above the 3-ppm level they tend to be lower. The more serious discrepancy, lying outside the limits of reproducibility (Table 3) of the spectrographic method, is in the analy- ses of the Henbury meteorite. As all determinations were made on the meteorite specimen used by Goldberg et al. [1951], the observed discrepancy would appear to indicate that appreciable fluctuation exist in the chemical composition of the meteorite. It is possible, however, that samples of this meteorite might have been accidentally mixed with another.

The comparison presented in Table 5 shows that whereas the three sets of the determined $R u$, $\mathrm{Rh}, \mathrm{Pd}$, and $\mathrm{Pt}$ values of Yavnel' [1950] are generally of poor precision, his selected values, except that for Pd, agree closely with our values.

As for Ir, it is clear from Table 6 that the spectrographic method yields values that are in good agreement with those obtained by neutron activation. The fact that Yavnel' [1950] did not detect $\mathrm{Ir}$ in the Sıkhote-Alin iron meteorite spectrographically (footnote, Table 5) provides an independent check, even though only qualitative, on those of our spectrographic Ir values which are lower than $0.5 \mathrm{ppm}$ (Table 7).

\section{Results}

The concentrations of $\mathrm{Ru}, \mathrm{Rh}, \mathrm{Pd}, \mathrm{Ir}$, and $\mathrm{Pt}$ in twenty-four iron meteorites are given in 
TABLE 5. Ru, Rh, Pd, and Pt Contents of the Sikhote-Alin Meteorite

\begin{tabular}{ccccc}
\hline & $\begin{array}{c}\text { Ru, } \\
\text { ppm }\end{array}$ & $\begin{array}{c}\text { Rh, } \\
\text { ppm }\end{array}$ & $\begin{array}{c}\text { Pd, } \\
\text { ppm }\end{array}$ & $\begin{array}{c}\text { Pt, } \\
\text { ppm }\end{array}$ \\
\hline $\begin{array}{c}\text { Yavnel' }^{\prime} \\
(1950)^{*} \\
\text { Sample 1 }\end{array}$ & 0.4 & 0.2 & 2.8 & 2.4 \\
Sample 2 & 5.7 & 0.9 & 6.9 & 4.6 \\
Sample 3 & 3.4 & 0.8 & 2.0 & 2.7 \\
$\begin{array}{c}\text { Accepted } \\
\text { contents }\end{array}$ & 5.7 & 0.9 & 6.9 & 4.6 \\
This work & $5.0 \pm 0.1$ & $1.6 \pm 0.1$ & $\begin{array}{c}<1 \\
\text { (esti- } \\
\text { mated) }\end{array}$ \\
\hline
\end{tabular}

* High-temperature extraction of the metals into a lead globule followed by spectrographic determination. The highest of the three sets of values selected because the low values are believed to be the result of probable high-temperature volatilization losses of the metals. Analytical error is estimated to be about $20 \%$. Ir and Os have not been detected. Sample sizes in the range of $25 \mathrm{~g}$.

Table 7. The corresponding concentrations in the metal phases of five ordinary chondrites, together with the observed proportions of these phases, are given in Table 8.

$R u-R h$ and $I r-P t$ groups. The Ru contents of the iron meteorites are plotted against the $\mathrm{Rh}$ contents in Figure 1, and the Ir contents of the meteorites are plotted against the $\mathrm{Pt}$ contents in Figure 2. Inspection of the figures shows that the $\mathrm{Ru}$ and $\mathrm{Ir}$ levels are concentrated in three well-separated and mutually corresponding regions which for convenience we called Ru-Rh groups I, II, and III and Ir-Pt groups I, II, and III. The ranges of concentration associated with each of the groups are as follows:

\begin{tabular}{ccccc} 
Ru-Rh Groups & & \multicolumn{2}{c}{ Ir-Pt Groups } \\
\cline { 1 - 1 } \cline { 5 - 6 } $\mathrm{Ru}$, & $\mathrm{Rh}$, & & $\mathrm{Ir}$, & $\mathrm{Pt}$, \\
$\mathrm{ppm}$ & $\mathrm{ppm}$ & & $\mathrm{ppm}$ & $\mathrm{ppm}$
\end{tabular}

Group I $\quad 11.9-21.5 \quad 1.7-2.5 \quad 7.6-15.3 \quad 11.8-29.3$

Group II $\quad 4.6-7.2 \quad 0.7-1.6 \quad 1.4-3.2 \quad 4.4-8.5$

Group III $<1.0 \quad<0.5 \quad<0.5 \quad 2.4-9.8$

Only one of the meteorites studied (Bear Creek) was found to have a Ru content and two (Edmonton and Tazewell) to have a Pt content lying outside these rather narrow limits. The remaining twenty-one meteorites are divided among the different groups in the following manner:

Of the nine meteorites belonging to $\mathrm{Ru}-\mathrm{Rh}$ group I, six belong to $\mathbf{I r}-\mathrm{Pt}$ group I; one belongs to Ir-Pt group III; and two belong to Ir-Pt group I on the basis of their Pt contents and to Ir-Pt group II on the basis of their Ir contents.

Of the twelve meteorites which belong to $\mathrm{Ru}-\mathrm{Rh}$ group II, as many as nine belong to $\mathrm{Ir}-\mathrm{Pt}$ group II; the remaining three belong to $\mathrm{Ir}-\mathrm{Pt}$ group III.

The only two meteorites which are in Ru-Rh group III do not belong to any of the Ir-Pt groups.

It is of interest that the $\mathrm{Ru} / \mathrm{Rh}$ ratio varies only from 5.7 to 10.3 for the meteorites of $\mathrm{Ru}-\mathrm{Rh}$ group $\mathrm{I}$, from 3.1 to 6.7 for those of group II, and from 1.6 to 3.2 for those of group III; the $\mathrm{Pt} / \mathrm{Ir}$ ratio varies from 1.2 to 3.7 for the meteorites of Ir-Pt group I, from 1.8 to 4.7 for those of group II, and from 6.0 to 33.8 for those of group III.

Structures and nickel contents. When the structures and the known Ni contents (Table 7) of the meteorites belonging to each $\mathrm{Ru}-\mathrm{Rh}$ and Ir-Pt group are examined, it is found that the meteorites of Ru-Rh group I and Ir-Pt group I have $\mathrm{Ni}$ contents lying between 5.5 and $16.5 \%$ and embrace hexahedrites, coarse and medium

TABLE 6. Ir Content of the Metal Phase of Ordinary Chondrites by Different Methods of Analysis

\begin{tabular}{|c|c|c|c|}
\hline $\begin{array}{l}\text { Name of } \\
\text { Mete- } \\
\text { orite }\end{array}$ & $\begin{array}{c}\text { Ir, ppm, } \\
\text { Neutron } \\
\text { Activation, }{ }^{*} \\
\text { Rushbrools and } \\
\text { Ehmann }[1962]\end{array}$ & Name & $\begin{array}{l}\text { Ir, ppm, } \\
\text { Spectro- } \\
\text { graphic, } \\
\text { This } \\
\text { Work }\end{array}$ \\
\hline Elenovka & 3.0 & Alamogordo & $3.0 \pm 0.3$ \\
\hline $\begin{array}{r}\text { Forest } \\
\text { City }\end{array}$ & 2.7 & Gilgoin Station & $2.6 \pm 0.3$ \\
\hline Okhansk & 3.0 & Okhansk & $2.9 \pm 0.4$ \\
\hline Plainview & 3.0 & Plainview & $3.2 \pm 0.6$ \\
\hline Pultusk & 2.4 & Gladstone & $2.1 \pm 0.2$ \\
\hline $\begin{array}{c}\text { Average } \\
\text { value }\end{array}$ & 2.85 & $\begin{array}{c}\text { Average } \\
\text { value }\end{array}$ & $2.8 \pm 0.4$ \\
\hline
\end{tabular}

* Complete samples of the chondrites were analyzed for Ir and the results normalized to the known metal phase content, assuming $100 \%$ siderophile character of the element. 
TABLE 7. Ru, Rh, Pd, Ir, and Pt Contents of Iron Meteorites

\begin{tabular}{|c|c|c|c|c|c|c|c|}
\hline $\begin{array}{l}\text { Name of } \\
\text { Meteorite }\end{array}$ & Type* & $\underset{\%}{\mathrm{Ni}, \dagger}$ & $\begin{array}{l}\text { Ru, } \\
\text { ppm }\end{array}$ & $\begin{array}{l}\text { Rh, } \\
\text { ppm }\end{array}$ & $\begin{array}{l}\text { Pd, } \\
\text { ppm }\end{array}$ & $\begin{array}{l}\text { Ir, } \\
\text { ppm }\end{array}$ & $\begin{array}{l}\mathrm{Pt}, \\
\mathrm{ppm}\end{array}$ \\
\hline Altonah & Of & 8.56 & $4.7 \pm 0.1$ & $0.7 \pm 0.1$ & $4.2 \pm 0.1$ & $1.6 \pm 0.2$ & $5.1 \pm 0.6$ \\
\hline Arispe & $\mathrm{Og}$ & 6.77 & $13.7 \pm 1.5$ & & & & $17.2 \pm 0.1$ \\
\hline Bear Creek & $\mathrm{Om}$ & 10.14 & $2.5 \pm 0.4$ & $1.5 \pm 0.3$ & $5.4 \pm 0.6$ & $<\overline{0.4}$ & $2.4 \pm 0.1$ \\
\hline Bendego & $\mathrm{Og}$ & 68 & $11.9 \pm 0.7$ & $2.1 \pm 0.4$ & $2.7 \pm 0.9$ & $0.3 \pm 0.1$ & $9.8 \pm 1.0$ \\
\hline Bristol & Off & 8.15 & $5.1 \pm 1.2$ & $0.8 \pm 0.1$ & $3.9 \pm 0.3$ & $1.7 \pm 0.4$ & $5.0 \pm 0.6$ \\
\hline Canyon Diablo & $\mathrm{Og}$ & 718 & $6.4 \pm 0.4$ & $1.5 \pm 0.1$ & $3.6 \pm 0.2$ & $1.8 \pm 0.2$ & $7.4 \pm 0.7$ \\
\hline Cape of Good Hope & $D_{1}$ & 16.48 & $13.3 \pm 0.2$ & $1.7 \pm 0.3$ & $4.1 \pm 0.1$ & $8.5 \pm 2.1$ & $11.8 \pm 0.2$ \\
\hline Coahuila & $\mathrm{H}$ & 5.65 & $23.7 \pm 2.5$ & $2.3 \pm 0.1$ & $2.0 \pm 0.1$ & $14.8 \pm 0.1$ & $24.2 \pm 0.1$ \\
\hline Costilla Peak & $\mathrm{Om}$ & 7.59 & & & & $15.3 \pm$ & $17.7 \pm 3.3$ \\
\hline Coya Norte & $\mathrm{H}$ & 5.5 & 15.2 & 2.5 & $1.8=$ & $3.3 \pm$ & $=5.6$ \\
\hline & Off-Of & 12.66 & & 0.3 & & $0.6=$ & 0.1 \\
\hline ake & $\mathrm{Om}$ & & 5 & 1.2 & 3.9 & $2.2=$ & $=0.7$ \\
\hline Hen & $\mathrm{Om}$ & 7. & 6.0 & 1.2 & 3.9 & $2.3=$ & $=0.8$ \\
\hline & Of & & & & & & $=0.3$ \\
\hline Indian Valley & $\mathrm{H} ; \mathrm{D}_{2} \mathrm{gr}-\mathrm{H}$ & 5.64 & $21.0 \pm 1.2$ & 2.1 & & $7.9 \pm$ & $29.3 \pm 2.6$ \\
\hline & $\mathrm{Om}-\mathrm{Of}$ & & & & & & \\
\hline tt Tabby (?) & $\mathrm{Og}$ & 6.8 & 16.6 & 2.2 & 3.0 & $9.1 \pm$ & $23.5 \pm 1.6$ \\
\hline & Og-Ogg & 7.40 & $6.0 \pm 0.1$ & $1.4 \pm$ & $3.7 \pm 0.2$ & $1.8 \pm 0.1$ & $8.5 \pm 0.4$ \\
\hline Rio I & $\mathbf{H}$ & 5.70 & & & & $3.4 \pm 0.6$ & $26.9 \pm 4.6$ \\
\hline Mountains & $\mathrm{Hgr}$ & 5.8 & $7.2 \pm 1.0$ & $1.5 \pm 0.3$ & $2.1 \pm 0.4$ & $<\overline{0.4}$ & $9.0 \pm 1.0$ \\
\hline Sikhot & Hgr-Ogg & & & & & & \\
\hline & $\mathrm{Om}_{\mathrm{m}}$ & 8. & & $1.2 \pm 0.1$ & & $0.4 \pm 0.1$ & $6.7 \pm 0.2$ \\
\hline & Off & 16. & $0.5 \pm 0.1$ & $0.14 \pm 0.01$ & & & $0.5 \pm 0.1$ \\
\hline Toluca & $\mathrm{Om}$ & 8.31 & $5.3 \pm 0.4$ & $1.1 \pm 0.1$ & $4.0 \pm 0.2$ & $2.0 \pm 0.1$ & $6.5 \pm 0.9$ \\
\hline
\end{tabular}

* According to Prior [1953] and Lovering et al. [1957].

$\dagger$ According to Goldberg et al. [1951], Lovering et al. [1957], and Yavnel' [1954].

octahedrites, according to the classification proposed by Lovering et al. [1957], and also a $\mathrm{Ni}$ rich ataxite. The former group contains about $70 \%$ and the latter about $30 \%$ of the hexahedrites studied. The lower Ni boundaries of the two groups appear to lie in the neighborhood of $5.5 \%$.

The meteorites of $\mathrm{Ru}-\mathrm{Rh}$ group II and Ir-Pt group II, each of which contains about one-half of the meteorites studied, range in $\mathrm{Ni}$ content

TABLE 8. Ru, Rh, Pd, Ir, and Pt Contents of the Metal Phase of Chondrites

\begin{tabular}{|c|c|c|c|c|c|c|c|}
\hline $\begin{array}{l}\text { Name of } \\
\text { Meteorite }\end{array}$ & Class & $\begin{array}{c}\text { Metal } \\
\text { Phase, } \\
\%\end{array}$ & $\begin{array}{l}\text { Ru, } \\
\text { ppm }\end{array}$ & $\begin{array}{l}\text { Rh, } \\
\text { ppm }\end{array}$ & $\begin{array}{l}\text { Pd, } \\
\text { ppm }\end{array}$ & $\begin{array}{l}\text { Ir, } \\
\text { ppm }\end{array}$ & $\begin{array}{l}\text { Pt, } \\
\text { ppm }\end{array}$ \\
\hline Alamogordo & $\begin{array}{l}\text { Crystalline spherical } \\
\text { chondrite }\end{array}$ & 13.5 & $6.1 \pm 0.8$ & $0.9 \pm 0.1$ & $4.2 \pm 0.6$ & $3.0 \pm 0.3$ & $7.9 \pm 0.4$ \\
\hline Gilgoin Station & $\begin{array}{l}\text { Crystalline bronzite } \\
\text { chondrite }\end{array}$ & 19.6 & $5.4 \pm 0.2$ & $1.0 \pm 0.2$ & $3.7 \pm 0.3$ & $2.6 \pm 0.3$ & $8.0 \pm 1.6$ \\
\hline Gladstone & $\begin{array}{l}\text { Black-veined crystalline } \\
\text { spherical chondrite }\end{array}$ & 15.4 & $5.9 \pm 0.3$ & $1.0 \pm 0.1$ & $3.9 \pm 0.2$ & $2.1 \pm 0.2$ & $8.5 \pm 1.4$ \\
\hline Okhansk & $\begin{array}{l}\text { Polymict brecciated } \\
\text { spherical bronzite } \\
\text { chondrite }\end{array}$ & 20.8 & $6.2 \pm 0.6$ & $1.1 \pm 0.1$ & $3.7 \pm 0.1$ & $2.9 \pm 0.4$ & $9.1 \pm 1.7$ \\
\hline Plainview & $\begin{array}{l}\text { Polymict brecciated } \\
\text { veined intermediate } \\
\text { chondrite }\end{array}$ & 15.0 & $6.5 \pm 0.4$ & $1.0 \pm 0.1$ & $4.7 \pm 0.3$ & $3.2 \pm 0.6$ & $9.0 \pm 0.9$ \\
\hline
\end{tabular}




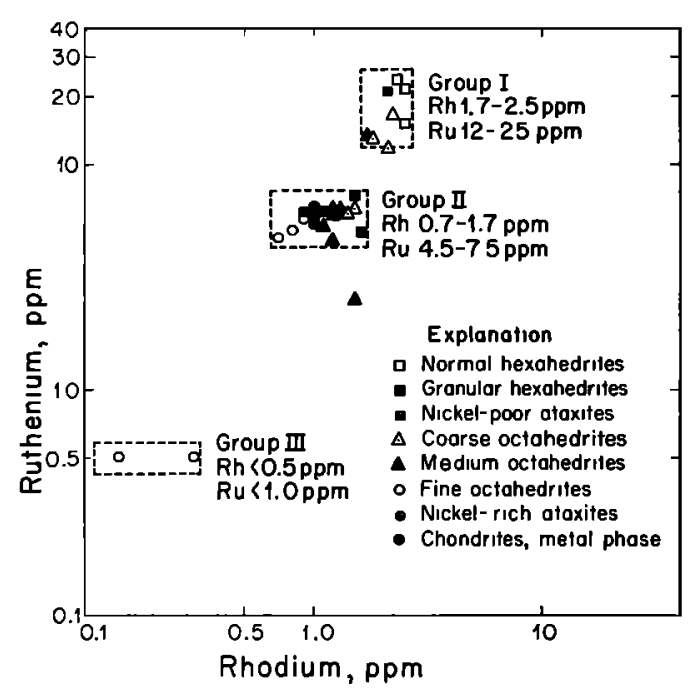

Fig. 1. Relation between $\mathrm{Ru}$ and $\mathrm{Rh}$ contents of meteorites.

from 5.5 to $9.0 \%$ and consist chiefly of medium and fine octahedrites.

The two meteorites of $\mathrm{Ru}-\mathrm{Rh}$ group III have $\mathrm{Ni}$ contents of 12.7 and $16.7 \%$ and are fine octahedrites; the five meteorites of Ir-Pt group III range in $\mathrm{Ni}$ content between 5.7 and $\mathbf{1 0 . 1 \%}$ and encompass hexahedrites and medium and coarse octahedrites.

\section{Correlations}

Ga-Ge groups. It will be recalled that the ranges of concentration in the four known Ga-Ge groups are as follows:

$\begin{array}{lcc} & \text { Ga, ppm } & \text { Ge, ppm } \\ \text { Group I } & 80-100 & 300-420 \\ \text { Group II } & 40-65 & 130-230 \\ \text { Group III } & 8-24 & 15-80 \\ \text { Group IV } & 1-3 & <1-1\end{array}$

Of these four groups, Ga-Ge groups II, III, and IV, which comprise twenty out of the twenty-four meteorites examined in this study, are represented in the correlations shown in Table 9. It is interesting to note that the meteorites of $\mathrm{Ru}-\mathrm{Rh}$ group I and $\mathrm{Ir}-\mathrm{Pt}$ group I without exception belong to $\mathrm{Ga}-\mathrm{Ge}$ group II, whereas the meteorites of $\mathrm{Ru}-\mathrm{Rh}$ group II and and Ir-Pt group II can belong to either Ga-Ge group II or group IV. Since there are no meteorites among those listed in the table which belong to both Ru-Rh group III and Ir-Pt group III, the relationships, if any, between these groups and $\mathrm{Ga}-\mathrm{Ge}$ groups, in particular Ga-Ge group III, are not completely clear.

A more comprehensive picture of the general relationships between the groups, structural classes, and $\mathrm{Ni}$ contents of the meteorites is shown in Figure 3, where $\mathrm{Ni}$ concentration is plotted against kamacite bandwidth in order of decreasing coarseness. The $\mathrm{Ru}-\mathrm{Rh}, \mathrm{Ir}-\mathrm{Pt}$, and Ga-Ge groups are found to be only nonuniquely associated with the well-defined structural fields, as shown in Figure 3. Meteorites lying within any of these fields will with high probability have $\mathrm{Ru}, \mathrm{Rh}, \mathrm{Ir}, \mathrm{Pt}, \mathrm{Ga}$, and Ge contents corresponding to any of the three $\mathrm{Ru}-\mathrm{Rh}, \mathrm{Ir}-\mathrm{Pt}$, and Ga-Ge groups, thus making it appear that there is little or no immediately discernible relationship between structure and $\mathrm{Ga}-\mathrm{Ge}, \mathrm{Ru}-\mathrm{Rh}$, and Ir-Pt groups.

Palladium. The behavior of $\mathrm{Pd}$ was found to be quite different from that of $\mathrm{Ru}, \mathrm{Rh}, \mathrm{Ir}$, and Pt. While the $\mathrm{Ru}, \mathrm{Rh}, \mathrm{Ir}$, and Pt concentrations generally increase with increasing concentration of one another, the Pd concentration, which varies only over the relatively narrow range of 1.45 to $6.47 \mathrm{ppm}$, decreases with increasing concentration of each of these metals. Although the $\mathrm{Ru}, \mathrm{Rh}, \mathrm{Ir}$, and Pt concentrations generally decrease with increasing $\mathrm{Ni}$ concentration and decreasing kamacite bandwidth, the Pd concentration increases.

Goldberg et al. [1951] pointed out that $\mathrm{Pd}$

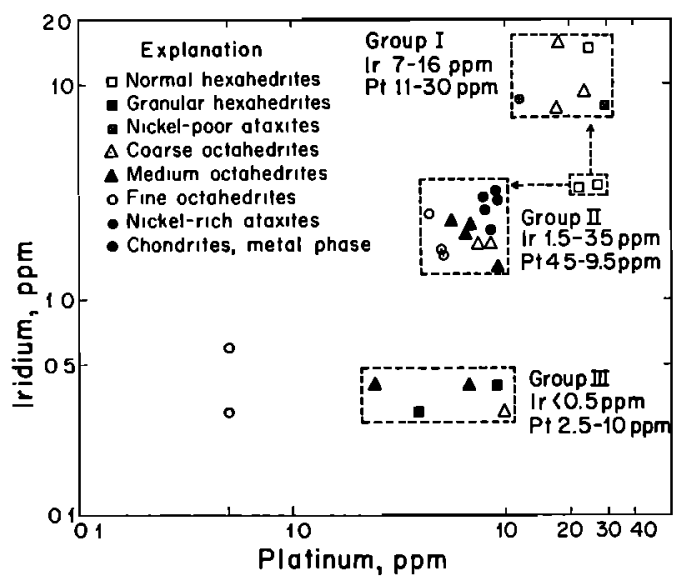

Fig. 2. Relation between $\mathrm{Ir}$ and $\mathrm{Pt}$ contents of meteorites. 
TABLE 9. Correlations between Ru-Rh, Ir-Pt, and Ga-Ge Groups [Lovering et al., 1957]

\begin{tabular}{lcccc}
\hline \multicolumn{1}{c}{$\begin{array}{c}\text { Name of } \\
\text { Meteorite }\end{array}$} & Type & $\begin{array}{c}\text { Ru-Rh } \\
\text { Group }\end{array}$ & $\begin{array}{c}\text { Ir-Pt } \\
\text { Group }\end{array}$ & $\begin{array}{c}\text { Ga-Ge* } \\
\text { Group }\end{array}$ \\
\hline Altonah & Of & II & II & IV \\
Arispe & Og & I & I & II \\
Bear Creek & Om & Anomalous & III & III \\
Bendego & Og & I & III & II \\
Bristol & Off & II & II & IV \\
Canyon Diablo & Og & II & II & Anomalous \\
Cape of Good Hope & DI & I & I & Not determined \\
Coahuila & H & I & I & II \\
Costilla Peak & Om & I & I & Not determined \\
Coya Norte & H & I & I-II & II \\
Edmonton & Off-Of & III & Anomalous & III \\
Goose Lake & Om & II & II & II \\
Henbury & Om & II & II & II \\
Huizopa & Of & II & II & IV \\
Indian Valley & Dggr-H & I & I & II \\
Moonbi & Om-Of & II & II & Anomalous \\
Mount Tabby & Og & I & I & II \\
Odessa & Og & II & II & Not determined \\
Rio Loa & H & I & I-II & II \\
Sandia Mountaing & Hgr & II & III & II \\
Sikhote-Alin & Hgr-Ogg & II & III & Not determined \\
Spearman & Om & II & III & III \\
Tazewell & Off & III & Anomalous & IV \\
Toluca & Om & II & II & II \\
\hline
\end{tabular}

* None of the eight meteorites belonging to Ga-Ge group I has been examined for $\mathrm{Ru}, \mathrm{Rh}, \mathrm{Ir}$, and $\mathrm{Pt}$ in this study.

concentration increases with increasing $\mathrm{Ni}$ concentration but decreases with increasing $\mathrm{Ga}$ concentration. They showed that for a given $\mathrm{Ni}$ content, the meteorites belonging to Ga class II have lower Pd contents than the meteorites belonging to Ga classes I and III. More recently Hara and Sandell [1960], in a paper on the meteoritic abundance of $\mathrm{Ru}$, have concluded independently on the basis of their own Ru determinations on thirteen iron meteorites and the $\mathrm{Pd}$ values of Goldberg et al. for these same meteorites that $\mathrm{Pd}$ concentration generally decreases with increasing $\mathrm{Ru}$ concentration.

In general, whereas hexahedrites and coarse octahedrites have the highest $\mathrm{Ru}, \mathrm{Rh}, \mathrm{Ir}$, and $\mathrm{Pt}$ contents and fine octahedrites have the lowest, the same hexahedrites have the lowest Pd content and the fine octahedrites have the highest. A significant exception to these trends is Cape of Good Hope. This is a meteorite of very fine structure; yet the $\mathrm{Ru}, \mathrm{Rh}, \mathrm{Ir}$, and $\mathrm{Pt}$ contents appear much too high, considering the trends observed. The $\mathrm{Pd}$ content of this meteorite appears much too low considering these same trends. The behavior of $\mathrm{Pd}$ and that of $\mathrm{Ru}, \mathrm{Rh}, \mathrm{Ir}$, and $\mathrm{Pt}$ in relation to one another and also in relation to $\mathrm{Ni}$ is illustrated diagramatically in Figures 4 through 6.

In general, meteorites of low $\mathrm{Pd}$ content (1.5 to $3.5 \mathrm{ppm}$ ) tend to fall into $\mathrm{Ru}-\mathrm{Rh}$ group $\mathrm{I}$,

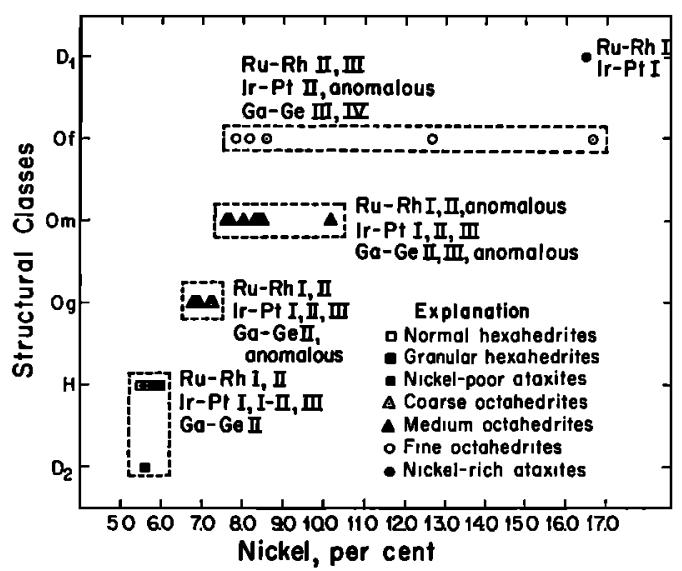

Fig. 3. Relation between structural classes, $\mathrm{Ni}$ content and $\mathrm{Ru}-\mathrm{Rh}, \mathrm{Ir}-\mathrm{Pt}$, and $\mathrm{Ga}-\mathrm{Ge}$ groups. 


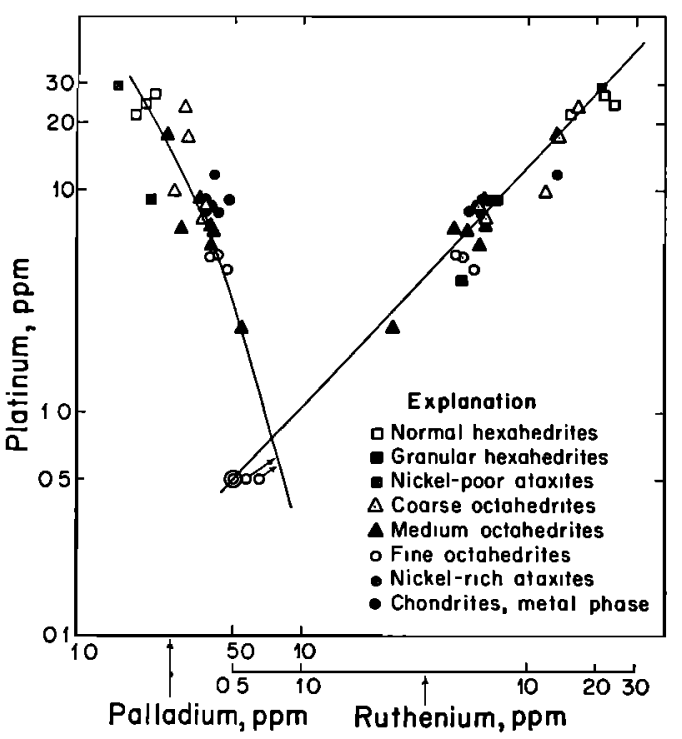

Fig. 4. Relations between $\mathrm{Pd}$ and $\mathrm{Pt}$ and between $\mathrm{Ru}$ and $\mathrm{Pt}$ contents of meteorites.

Ir-Pt group I, and Ga-Ge group II; meteorites with intermediate $P d$ contents (3.5 to $5.0 \mathrm{ppm}$ ) tend to fall into Ru-Rh group II, Ir-Pt group II, and $\mathrm{Ga}-\mathrm{Ge}$ group II or IV; and meteorites with high $\mathrm{Pd}$ contents (greater than $5.0 \mathrm{ppm}$ ), of which only three are represented here, tend to fall into Ga-Ge group III or IV and into $\mathrm{Ru}-\mathrm{Rh}$ group III or Ir-Pt group III.

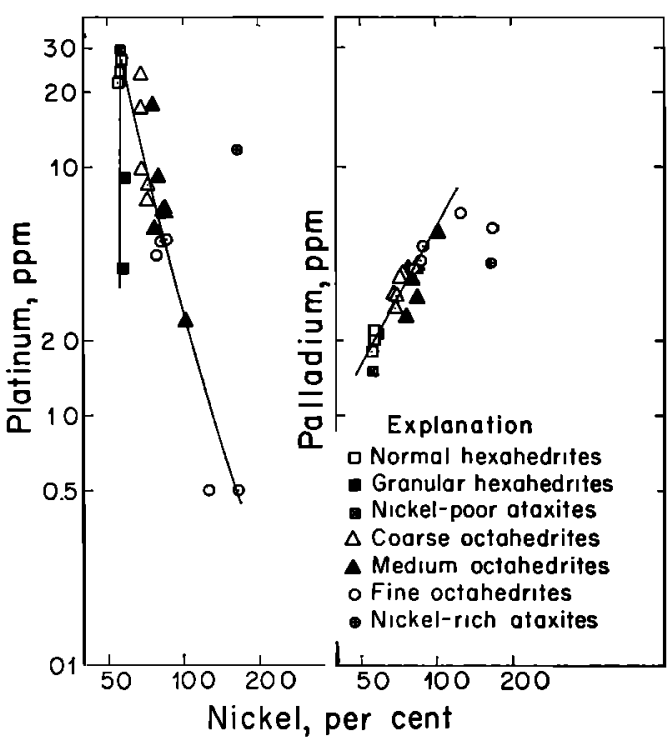

Fig. 5. Variation of $\mathrm{Pd}$ and $\mathrm{Pt}$ contents of meteorites with $\mathrm{Ni}$ content.

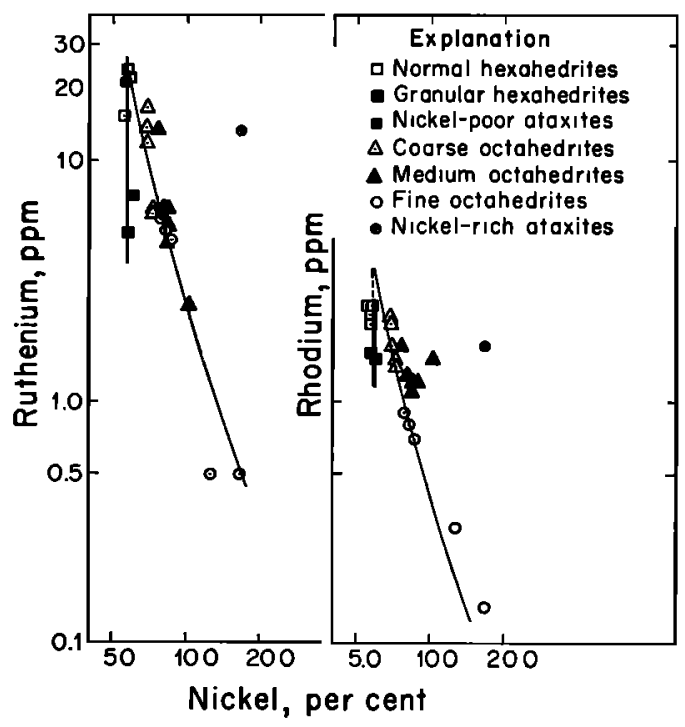

Fig. 6. Variation of Ru and $\mathrm{Rh}$ contents of meteorites with $\mathrm{Ni}$ content.

Similarity of Canyon Diablo and Odessa. Goldberg et al. observed that three pairs of meteorites, namely Canyon Diablo-Odessa, Henbury-Costilla Peak, and Altonah-Bristol, have compositions and structures which are quite close to each other. They pointed out that of these pairs only Canyon Diablo-Odessa is made up of meteorites which lie close to each other geographically. The Odessa craters lie about 600 miles east-southeast of Meteor Crater, Arizona. It is apparent also from this work that Canyon Diablo and Odessa are very similar in composition, as shown in Table 10, where these two meteorites are listed along with two other pairs of very similar meteorites.

TABLE 10. Pairs of Meteorites of Similar Compositions

Name of $\mathrm{Ni}, \mathrm{Ru}, \mathrm{Rh}, \mathrm{Pd}, \mathrm{Ir}, \mathrm{Pt}$, Meteorite Class \% ppm ppm ppm ppm ppm

$\begin{array}{llllllll}\begin{array}{l}\text { Canyon } \\ \text { Diablo }\end{array} & \text { Og } & 7.18 & 6.4 & 1.5 & 3.6 & 1.8 & 7.4 \\ \text { Odessa } & \text { Og } & 7.24 & 6.0 & 1.4 & 3.7 & 1.8 & 8.5 \\ \text { Goose Lake } & \text { Om } & 8.46 & 6.4 & 1.2 & 3.9 & 2.2 & 6.8 \\ \text { Henbury } & \text { Om } & 7.66 & 6.0 & 1.2 & 3.9 & 2.3 & 5.6 \\ \text { Altonah } & \text { Of } & 8.56 & 4.7 & 0.7 & 4.2 & 1.6 & 5.1 \\ \text { Bristol } & \text { Of } & 8.15 & 5.1 & 0.8 & 3.9 & 1.7 & 5.0\end{array}$


TABLE 11. Dissimilar Pt and Pd Metal Contents of Hexahedrites

\begin{tabular}{|c|c|c|c|c|c|c|}
\hline $\begin{array}{l}\text { Name of } \\
\text { Meteorite }\end{array}$ & $\begin{array}{l}\mathrm{Ni} \\
\%\end{array}$ & $\begin{array}{l}\mathrm{Ru}, \\
\mathrm{ppm}\end{array}$ & $\begin{array}{l}\text { Rh, } \\
\text { ppm }\end{array}$ & $\begin{array}{l}\text { Pd, } \\
\text { ppm }\end{array}$ & $\begin{array}{l}\text { Ir, } \\
\text { ppm }\end{array}$ & $\begin{array}{l}\text { Pt, } \\
\text { ppm }\end{array}$ \\
\hline Coahuila & 5.56 & 23.7 & 2.3 & 2.0 & 14.8 & 24.2 \\
\hline Coya Norte & 5.5 & 15.2 & 2.5 & 1.8 & 33 & 21.9 \\
\hline $\begin{array}{l}\text { Indian } \\
\text { Valley }\end{array}$ & 564 & 21.0 & 2.1 & 1.5 & 7.9 & 293 \\
\hline Rio Loa & 570 & 21.5 & 2.5 & 2.2 & 3.4 & 26.9 \\
\hline $\begin{array}{l}\text { Sandia } \\
\text { Mountains }\end{array}$ & 5.94 & 7.2 & 1.5 & 2.1 & $<0.4$ & 9.0 \\
\hline Sikhote-Alin & 5.68 & 50 & 16 & & $<0.3$ & 3.9 \\
\hline
\end{tabular}

It is interesting to note that the date of fall of Canyon Diablo has been estimated [Anders, 1963] at $\geq 2700$ years ago and that of Odessa at $\geq 1400$ and even at $\geq 2900$ years ago. These estimates are based on the content of the cosmicray-produced $\mathrm{Ar}^{30}$ (325 years half-life) and $\mathrm{Cl}^{39}$ (308,000 years half-life), as reported by various investigators. The $\mathrm{C}^{14}$ content of Odessa, as determined by Goel and Kohman [1962], gives a date of fall more than 11,000 years ago. From the chemical similarities given above and these limiting dates of fall, it appears that the final proof as to whether Canyon Diablo and Odessa are really fragments of the same shower of irons will depend upon further measurements of the cosmic-ray-induced activities.

Dissimilarities among hexahedrites. Henderson [1941] noted that hexahedrites found in widely separated areas of the world are frequently indistinguishable from one another on the basis of their Ni contents. Goldberg et al. [1951] confirmed the earlier observation on the hexahedrites and stated further that individual hexahedrites are frequently identical with respect to their trace constituents.
In this work, hexahedrites were frequently found to be dissimilar in trace element contents, as can be seen from inspection of Table 11. The greatest of these dissimilarities appears to be related to the physical structures of the hexahedrites. The normal hexahedrites (Coahuila, Coya Norte, Rio Loa), which are made up of a uniform kamacite phase, have high concentrations of $\mathrm{Ru}, \mathrm{Ir}$, and $\mathrm{Pt}$; whereas the granular hexahedrites (Sandia Mountains, Sikhote-Alin), which are made up of separate crystals of kamacite, have low concentrations of these elements, in particular markedly low concentrations of Ir. These relationships between the structures of the hexahedrites and their trace constituents can be found from the graphs in Figures 5 and 6, where all hexahedrites lie on separate branches of the curves representing the behavior of $\mathrm{Pt}$ and $\mathrm{Pd}$ metals as a function of $\mathrm{Ni}$ content.

Chondrites. The five chondrites examined in this study contain 13 to $21 \%$ metallic phase and are classified as belonging to the high-iron group of Urey and Craig [1953]. With the exception of Okhansk, which has been previously classified by Wiik [1956], these classifications are new and are taken from analyses of stony meteorites by $\mathrm{X}$-ray fluorescence [Nichiporuk et al., 1965].

It is evident that the metal phases of the highiron-group chondrites, unlike the highly variable metal phases of all iron meteorites studied, are nearly identical in $\mathrm{Pt}$ and $\mathrm{Pd}$ metal contents and are quite similar in these contents to the large group of coarse, medium, and fine octahedrites belonging to our $\mathrm{Ru}-\mathrm{Rh}$ group II and $\mathrm{Ir}-\mathrm{Pt}$ group II. Furthermore, with respect to $\mathrm{Ru}$, the metal phases of the high-iron-group chondrites are decidedly similar to the granular hexahedrites belonging to Ru-Rh group II.

This rather clear connection between highiron-group chondrites and the two mutually interlinked groups of iron meteorites suggests that perhaps other groups of chondrites, namely

TABLE 12. Average Concentrations of Five Pt and Pd Metals

\begin{tabular}{cccccc}
\hline Group & $\begin{array}{c}\mathrm{Ru}, \\
\mathrm{ppm}\end{array}$ & $\begin{array}{c}\mathrm{Rh}, \\
\mathrm{ppm}\end{array}$ & $\begin{array}{c}\mathrm{Pd}, \\
\mathrm{ppm}\end{array}$ & $\begin{array}{c}\mathrm{Ir}, \\
\mathrm{ppm}\end{array}$ & $\begin{array}{c}\mathrm{Pt}, \\
\mathrm{ppm}\end{array}$ \\
\hline $\begin{array}{c}\text { High-iron-group chondrites, } \\
\text { metal phase, 5 samples }\end{array}$ & $6.0 \pm 0.5$ & $0.98 \pm 0.10$ & $4.1 \pm 0.3$ & $2.8 \pm 0.4$ & $8.5 \pm 1.2$ \\
Iron meteorites, 24 samples & $9.2 \pm 0.8$ & $1.47 \pm 0.15$ & $3.5 \pm 0.6$ & $3.7 \pm 0.6$ & $11.0 \pm 1.3$ \\
\hline
\end{tabular}


TABLE 13. Abundances of Pt and Pd Metals, $\mathrm{Si}=10^{6}$

\begin{tabular}{|c|c|c|c|c|c|}
\hline Investigators & Ru & Rh & $\mathbf{P d}$ & Ir & Pt \\
\hline $\begin{array}{l}\text { This work, based on metal phase of high- } \\
\text { iron-group chondrites }\end{array}$ & 1.66 & 0.27 & 1.05 & 0.40 & 1.22 \\
\hline This work, based on iron meteorites & 1.44 & 0.23 & 0.521 & 0.31 & 0.89 \\
\hline Hara and Sandell [1960], chondrites & 1.5 & & & & \\
\hline $\begin{array}{l}\text { Bate and Huizenga [1963], } \\
\text { low-iron-group chondrites } \\
\text { high-iron-group chondrites }\end{array}$ & $\begin{array}{l}1.10 \\
1.63\end{array}$ & & & & \\
\hline $\begin{array}{l}\text { Schindewolf and Wahlgren [1960], } \\
\text { low-iron-Troup chondrites } \\
\text { high-iron-group chondrites }\end{array}$ & & $\begin{array}{l}0.23 \\
0.33\end{array}$ & & & \\
\hline Hamaguch et al. (1961), chondrites & & & 1.26 & 0.27 & 0.80 \\
\hline Rushbrook and Ehmann [1962], chondrites & & & & 0.38 & \\
\hline $\begin{array}{l}\text { Suess and Urey [1956], interpolated iron } \\
\text { meteorite values of Goldschmidt [1938] }\end{array}$ & 1.49 & 0.214 & $0.675^{*}$ & 0.821 & 1.625 \\
\hline $\begin{array}{l}\text { Cameron }[1959] \text {, nucleosynthesis and Suess } \\
\text { and Urey }[1956]\end{array}$ & 0.87 & 0.15 & 0.675 & 0.494 & 1.28 \\
\hline Clayton and Fowler [1961], nucleosynthesis & 0.83 & 0.13 & 0.601 & 0.39 & 0.80 \\
\hline
\end{tabular}

* Based on analyses of 45 iron meteorites by Goldberg et al. [1951].

low-iron-group and enstatite chondrites, are also chemically connected to particular groups of iron meteorites. It should be noted in this context that in the previous work [Lovering et al., 1957] the stony-iron meteorites, specifically the pallasites, were found to be very clearly linked in their $\mathrm{Ga}$ and $\mathrm{Ge}$ contents to a large group of iron meteorites composed mainly of medium octahedrites and belonging to $\mathrm{Ga}-\mathrm{Ge}$ group III.

Abundances of $P t$ and $P d$ metals. It is convenient at this point to calculate from the above data the atomic abundances of Pt and Pd metals and see how they compare with the abundances calculated by recent workers. The average values we have used are shown in Table 12. All average $\mathrm{Pd}$ values and the averages of the metal phase of chondrites are from quite uniformly distributed individual values and are straightforward. The averages of the iron meteorites are the summedup proportionately weighted averages of each $\mathrm{Ru}-\mathrm{Rh}$ and each $\mathrm{Ir}-\mathrm{Pt}$ group. Entries in Table 13 are in atomic abundances, and the calculations have been made assuming in the case of the iron meteorites a contribution to mean meteoritic matter of $10 \%$ [Suess and Urey, 1956; Ehmann, 1961] and in the case of the chondrites the contribution of the metal phase equal to the actually determined proportions by weight of that phase as listed in Table 8 . The abundances are relative to $\mathrm{Si}$ taken as $10^{\circ}$, and the calculations are based on an amount of Si of $17.2 \%$ by weight [Urey, 1964] for the high-iron-group chondrites and an average amount between that percentage and the $18.6 \%$ [Urey, 1964] in the low-iron-group chondrites for the iron meteorites after normalization to mean meteoritic matter. The results are shown in Tables 12 and 13.

Acknowledgments. We thank Elizabeth Bingham and Arthur Chodos for helping us with the spectrographic determinations. We are indebted to the following persons who made available samples of a number meteorites used in this investigation: E. P. Henderson of the United States National Museum, C. F. Frondel of Harvard University, A. A. Yavnel' of the Committee on Meteorites of the Soviet Academy of Sciences, and J. F. Lovering of the Australian National University. The sample of Mount Tabby was obtained through the generosity of the Geology Museum of the University of Utah.

This work was supported by the National Aeronautics and Space Administration, grant NsG 5660, and the Atomic Energy Commission, contract AT(11-1)-208. 


\section{REFERENCES}

Anders, E., Meteorite ages, in The Moon, Meteorites, and Comets, edited by G. P. Kuiper and B. Middlehurst, chapter 13 , pp. 402-495, The University of Chicago Press, 1963.

Bate, G. L., and J. R. Huizenga, Abundances of ruthenium, osmium and uranium in some cosmic and terrestrial sources, Geochim. Cosmochim. Acta, 27, 345-360, 1963.

Brown, $\mathrm{H}$., $\mathrm{A}$ table of relative abundances of $\mathrm{nu}-$ clear species, Rev. Mod. Phys., 21, 625-634, 1949.

Brown, H., and E. Goldberg, The neutron pile as a tool in quantitative analysis; the gallium and palladium content of iron meteorites, Science, 109(2832), 347-353, 1949.

Cameron, A. G. W., A revised table of abundances of the elements, Astrophs. J., 129, 676-699, 1959.

Clayton, D. D., and W. A. Fowler, Abundances of heavy nuclides, Ann. Phys. (N.Y.), 16, 51-68, 1961.

Dodson, R. W., G. J. Forney, and E. H. Swift, Extraction of ferric chloride from hydrochloric acid solutions by isopropl ether, J. Am. Chem. Soc., 68, 2573-2577, 1936.

Ehmann, W. D., Recent improvement in our knowledge of cosmic abundances, J. Chem. Educ., 38, 53-57, 1961.

Goel, P. S., and T. P. Kohman, Cosmogenic carbon-14 in meteorites and terrestrial ages of "finds" and craters, Science, 186, 875-876, 1962.

Goldberg, E., A. Uchiyama, and H. Brown, The distribution of nickel, cobalt, gallium, palladium and gold in iron meteorites, Geochem. Cosmochim. Acta, 2, 1-25, 1951.

Goldschmidt, V. M., Geochemische Verteilungsgesetze der Elemente, Skrifter Norske VidenskapsAkad. Oslo, I, Mat.-Naturv. Kl., 148 pp., 1938.

Goldschmidt, V. M., and Cl. Peters, Zur Geochemie der Edelmetalle, Nachr. Ges. Wiss., Göttingen, Math.-physik. Kl., no. 4, 377-401, 1932.

Hamaguchi, H., T. Nakai, and V. Endo (quoted by $\mathrm{H}$. Urey), in 'A review of atomic abundances in chondrites and the origin of meteorites,' Rev. Geophys., 2, 1-34, 1964.

Hara, T., and E. B. Sandell, Meteoritic abundance of ruthenium, Geochim. Cosmochim. Acta, 21, $145-150,1960$.

Henderson, E. P., Chilean hexahedrites and the composition of all hexahedrites, Am. Mineralogist, 26, 546-550, 1941.

Herr, W., E. Merz, P. Eberhardt, J. Geiss, C. Land, and P. Signer, Search for decay products of na- tural technetium, Geochim. Cosmochim. Acta, $14,158,1958$.

Kuroda, P. K., and E. B. Sandell, Geochemistry of molybdenum, Geochim. Cosmochim. Acta, 6, 3563, 1954.

Lovering, J. F., W. Nichiporuk, A. Chodos, and H. Brown, The distribution of gallium, germanium, cobalt, chromium, and copper in iron and stony-iron meteorites in relation to nickel content and structure, Geochim. Cosmochim. Acta, $11,263-278,1957$.

Nachtrieb, N. H., and R. E. Fryxell, The extraction of ferric chloride by isopropyl ether, $2, J$. Am. Chem. Soc., 70, 3552-3557, 1948.

Nichiporuk, W., and H. Brown, Platinum and iridium abundances in meteorites, Phys. Rev. Letters, 9, 245-246, 1962.

Nichiporuk, W., E. Helin, A. Chodos, and H. Brown, $\mathrm{X}$-ray fluorescence analysis of stony meteorites, to be published in Geochim. Cosmichim. Acta, 1965.

Noddack, I., and W. Noddack, Die Häufigkeit der chemischen Elemente, Naturwiss., 18, 757-764, 1930.

Prior, G. T., Catalogue of Meteorites, 432 pp., British Museum, London, 1953.

Rushbrook, P. R., and W. D. Ehmann, Iridium in stone meteorites by neutron activation, Geochim. Cosmochim. Acta, 26, 649-657, 1962.

Schindewolf, U., and M. Wahlgren, The rhodium, silver, and indium content of some chondritic meteorites, Geochim. Cosmochim. Acta, 18, 3641,1960 .

Suess, H. E., and H. C. Urey, Abundances of the elements, Rev. Mod. Phys., 28, 53-74, 1956.

Urey, H. C., A review of atomic abundances in chondrites and the origin of meteorites, Rev. Geophys., 2, 1-34, 1964.

Urey, H. C., and H. Craig, The composition of the stone meteorites and the origin of the meteorites, Geochim. Cosmochim. Acta, 4, 36-82, 1953.

Wiik, H. B., The chemical composition of some stony meteorites, Geochim. Cosmochim. Acta, 9 , 279-289, 1956.

Yavnel, A. A., Spectrographic analysis of the Sikhote-Alin meteorite (in Russian), Meteoritika, 8, 134-148, 1950.

Yavnel', A. A., Concerning the uniformity of the chemical composition of the Sikhote-Alin iron meteorite (in Russian), Meteoritika, II, 107116, 1954.

(Manuscript received July 20, 1964.) 